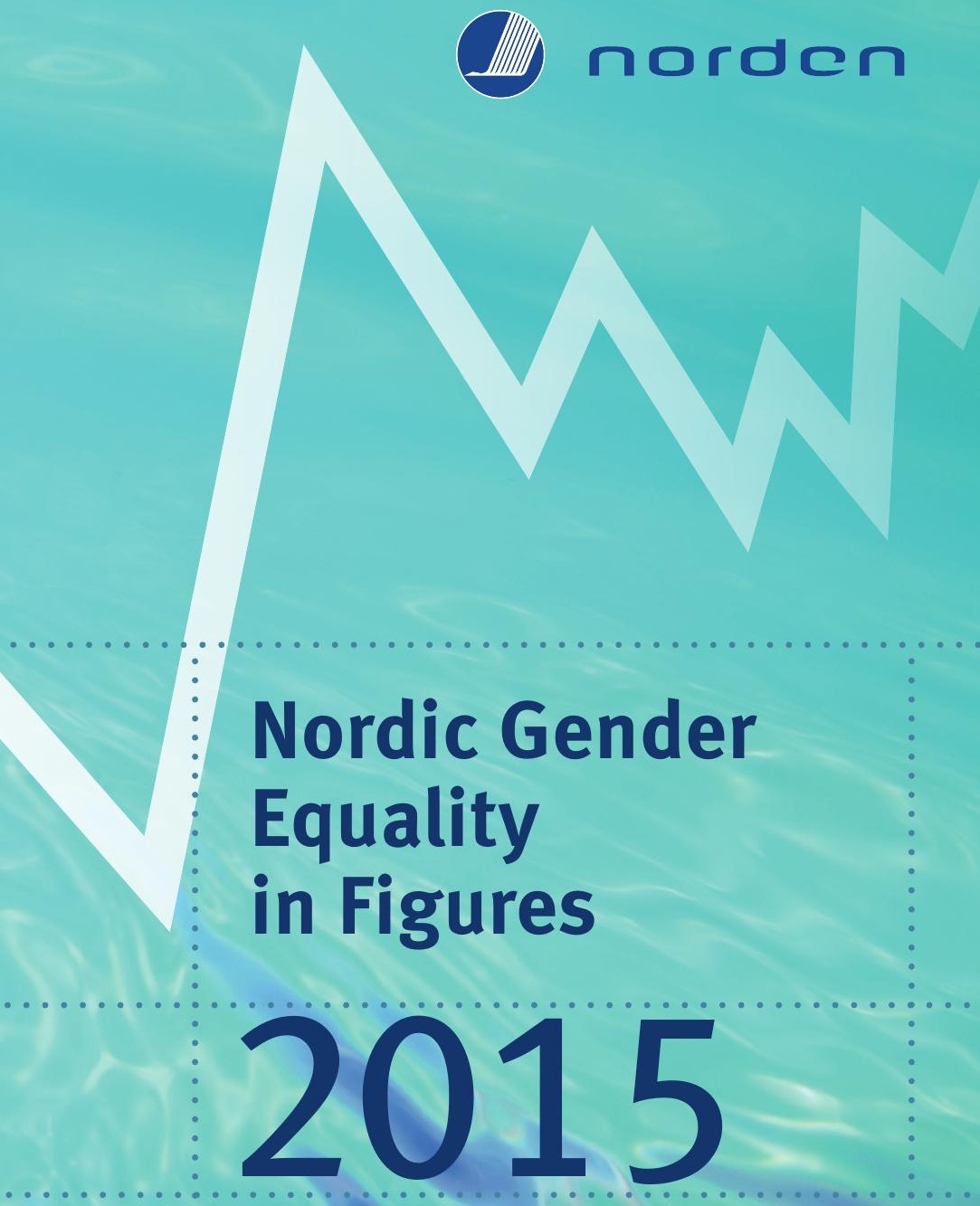




\section{Nordic Gender Equality in Figures 2015}

ISBN 978-92-893-4039-7 (PRINT)

ISBN 978-92-893-4040-3 (PDF)

ISSN 0908-4339

http://dx.doi.org/10.6027/ANP2015-733

ANP 2015:733

(C) Nordic Council of Ministers 2015

Cover design: Erling Lynder/SignElements

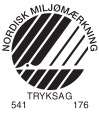

Nordic Council of Ministers

Ved Stranden 18

DK-1061 Copenhagen K

www.norden.org/en/publications

\section{Nordic co-operation}

Nordic co-operation is one of the world's most extensive forms of regional collaboration, involving Denmark, Finland, Iceland, Norway, Sweden, and the Faroe Islands, Greenland, and Åland.

Nordic co-operation has firm t aditions in politics, the economy, and culture. It plays an important role in European and international collaboration, and aims at creating a strong Nordic community in a strong Europe.

Nordic co-operation seeks to safeguard Nordic and regional interests and principles in the global community. Common Nordic values help the region solidify its position as one of the world's most innovative and competitive. 


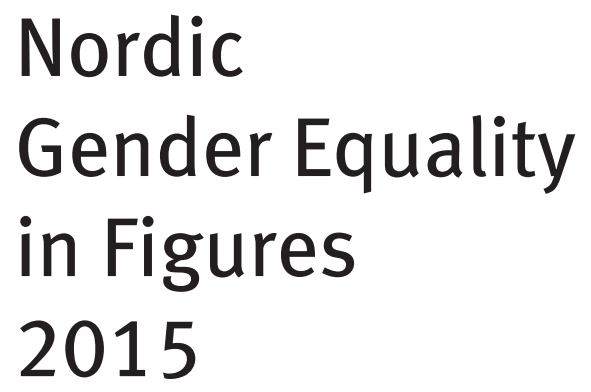

ANP 2015:733 


\section{Content}

\section{Demography 4}

1.1 Population pyramid 4

1.2 Fertility rates 6

1.3 Mean age at birth of first child 7

\section{Family and Care 8}

2.1 Families 8

2.2 Childlessness 9

2.3 Parental leave 10

2.4 Children in daycare 11

2.5 Time use on domestic work 12

\section{Health 13}

3.1 Life expectancy at birth 13

3.2 Self-perceived limitations due to health problems 14

3.3 Daily smoking 15

3.4 Mortality rates from cancer 16

3.5 Mortality rates from diseases of the circulatory system 17

3.6 Suicides 18

3.7 Abortion 19

3.8 Absence from work for at least a week due to illness 20

\section{Education 21}

4.1 Educational attainment 21

4.2 Early leavers from education and training 22

4.3 Graduated students at tertiary level 23

4.4 Attained tertiary education by field of education 24

\section{Labour market 25}

5.1 Labour market status 25

5.2 Segregation 26

5.3 Part-time work 27

\section{Income 29}

6.1 Gender pay gap 29

6.2 Mean annual earnings 30

6.3 People at risk of poverty 31

6.4 Relative median income ratio 32

\section{Influence and power 33}

7.1 Candidates elected to the national parliaments 33

7.2 Gender balance on boards 34

7.3 Gender differences among employers 35

7.4 Leaders and managers 36

\section{Symbols}

Nil Less than half 0

Not applicable Data not available

Denmark (DK) Faroe Islands (FO) EU
Greenland (GL)

Åland (AX) Iceland (IS)
Norway (NO)

Sweden (SE) 


\section{Foreword}

The co-operation on gender equality between the Nordic countries, the Faroe Islands, Greenland and Åland is driven by a shared vision of a gender-equal Nordic Region with equal opportunities, rights and obligations for all who live in the Region, regardless of gender. Gender equality is a fundamental value to the Nordic countries and is vital for economic and social growth.

Gender equality means that women and men, girls and boys have equal power and influence, and equal rights, responsibilities, obligations and opportunities in every area of life. This brochure briefly describes some important areas of life and society, such as family, work, education, health, power, income and influence. This data will hopefully be useful for everyone who seeks reliable and comparable data on gender equality in the Nordic countries.

The brochure, together with more information, is available online at www.norden.org.

This publication has been published with financial support by the Nordic Council of Ministers. However, the contents of this publication do not necessarily reflect the views, policies or recommendations of the Nordic Council of Ministers. 


\section{Demography}

\subsection{Population pyramid}

The population pyramid illustrates the composition of the population by age and sex. During the last 20 years the share of the young population, $0-19$ years, has decreased in all countries, except Denmark where it remains unchanged. The share of the older population, 65 or older, has increased in all Nordic countries. There is a slight increase in the share of the working-age population, 20-64

DK

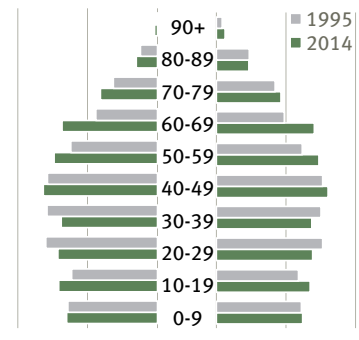

$\begin{array}{llllll}500 & 250 & 0 & 0 & 250 & 500\end{array}$ Thousand 4

$\mathrm{GL}$

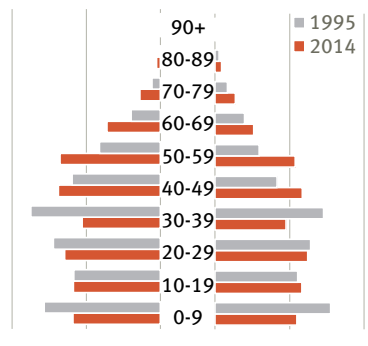

$\begin{array}{llllll}7 & 3,5 & 0 & 0 & 3,5 & 7 \\ & & \end{array}$ Thousand ${ }^{500}$

Men are shown to the left and women to the right
FO

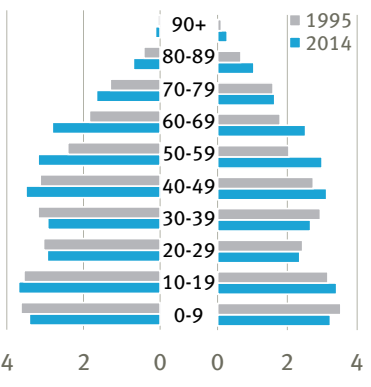

$\mathrm{FI}$

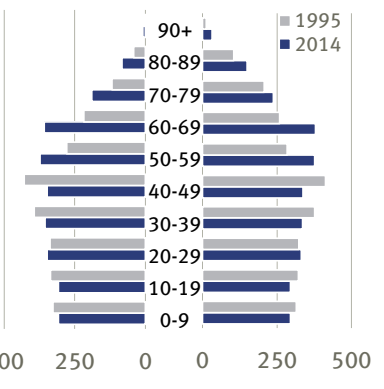


years, in Greenland, Iceland and Norway. The opposite applies in Denmark, Faroe Islands, Finland, Åland and Sweden. This is a general pattern that can be seen in many EU countries. Since all Nordic countries, except the Faroe Islands have a fertility rate below replacement level, it implies that relatively fewer people than before are refilling the working age group.

$\mathrm{AX}$

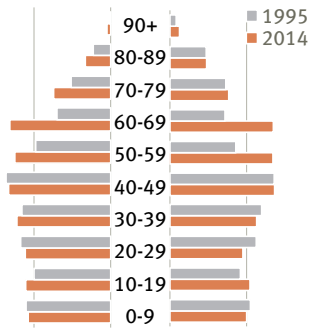

3
IS

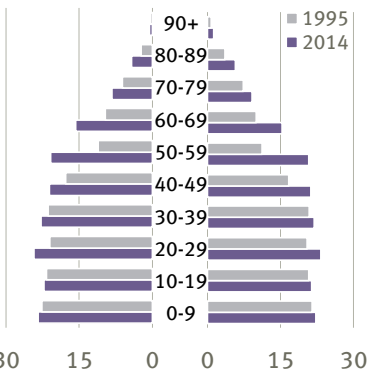

NO

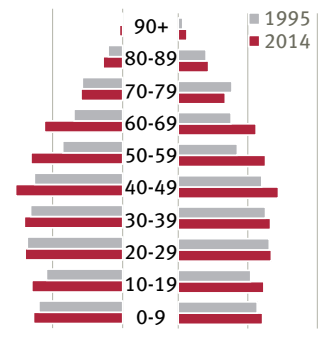

SE

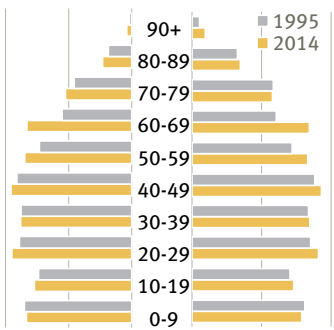

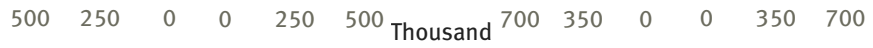

Men are shown to the left and women to the right

Source: POPUO1 in the database Nordic Statistics 


\subsection{Fertility rates}

The Total fertility rate is the number of live births per woman of childbearing age. 1.5 children per woman is a critical level of fertility rate. If fertility is below this level the proportion of elderly in the population increases and also the dependency ratio. 2.1 children are considered as a level where the population increases without support of immigration. Good access to childcare can facilitate the possibility of combining gainful employment and family life. In the Nordic countries good childcare and parental allowance are likely to keep up the fertility rate.

The fertility rates in the Nordic countries are higher than the average of EU which is 1.6 children per woman. The highest fertility rate is found in the Faroe Islands, 2.5 and the lowest in Finland and Denmark, 1.7.

\section{Fertility rates 1995-2013}

3.0

2.5

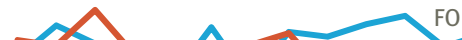

.5

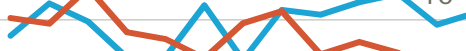

son

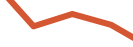

2.0

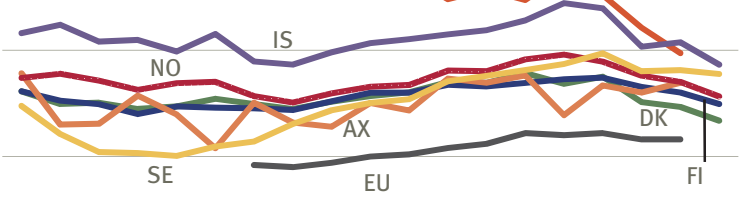

1.5

SE

EU

$\mathrm{FI}$

1.0

$\begin{array}{llllllllll}1995 & 1997 & 1999 & 2001 & 2003 & 2005 & 2007 & 2009 & 2011 & 2013\end{array}$

Source: CHILO2 in the database Nordic Statistics 


\subsection{Mean age at birth of first child}

The mean age of mothers at birth of their first child is about 29 years in all Nordic countries, except Iceland where the mothers are almost two years younger. In all countries, except Finland, the age is about two years higher compared to 1995, in Finland the increase is one year.

The fathers are two to three years older than the mothers when their first child is born. In the Nordic countries they are between 30 in Iceland, and 31.5 years in Sweden. Also the father's age has increased by between two and three years since 1995 .

\section{Mean age at birth of first child}

32

30

28

26

24

22

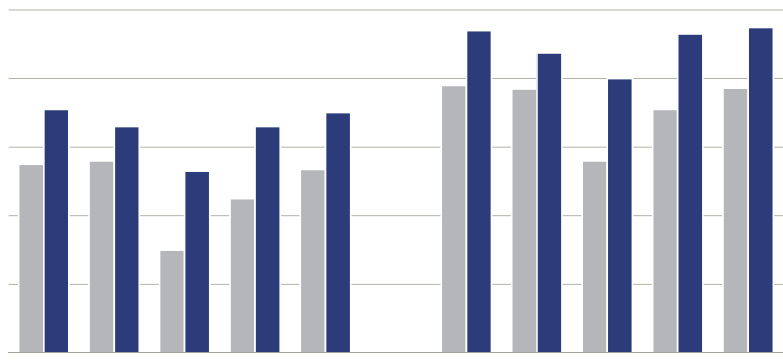

DK FI IS NO SE

Mothers

1995

DK FI IS NO SE

Fathers

- 2013

Source: Nordic Statistical Institutes 


\section{Family and Care}

\subsection{Families}

The family and housing circumstances of an individual change over the course of a lifetime. A family consists either of one person or several persons related to each other. Most families correspond to a household. A household includes all people, related or not, living at the same address, sharing a house or a flat. Consequently, households may include more than one family.

Nearly 40 per cent of the families in Iceland have children, in Norway and Denmark this is true of 27 per cent. Sweden and Finland have the lowest share of families with children in the Nordic countries. About four out of five families with children in the Nordic countries consist of married or cohabiting couples. The majority of single parents are mothers. Sweden has the highest proportion of single fathers.

\section{Families with and without children 0-17 years by type of family 2013} 100

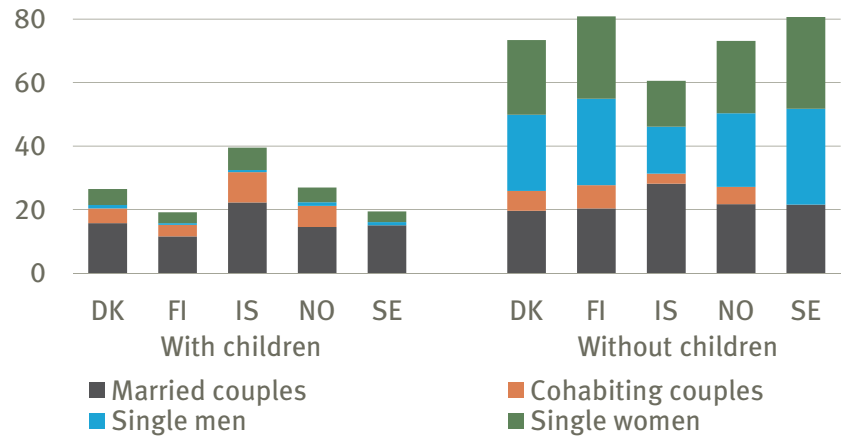

Note: DK: Children aged O-24. SE: Married include cohabiting couples Source: NOSOSCO: "Social protection in the Nordic Countries" 


\subsection{Childlessness}

The indicator on childlessness shows the share of women and men born in 1965 who have not had any children at the age of 45 .

Finland has the highest proportion of both men and women who have not become parents. 22 to 27 per cent of the men are childless where this is true for 10 to 19 per cent of the women in the Nordic countries.

\section{Childlessness for women and men born in 1965 by the age of 45} 30

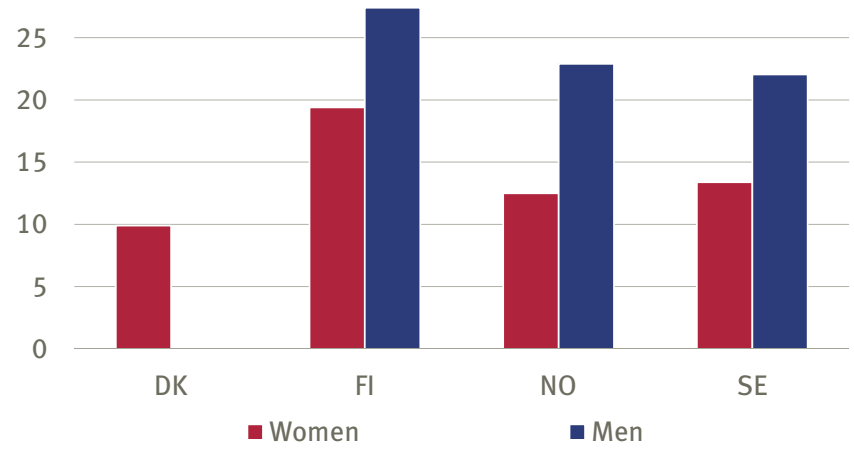

Note: DK: age 44 years. Fl: age 45-49 years

Source: Nordic Statistical institutions 


\subsection{Parental leave}

The indicator shows the number of days in which maternity and paternity benefits where drawn per new-born baby in the year. Both the number of recipients and days in which maternity and paternity benefit is payable vary considerably from one country to the other. Sweden has the longest parental leave period with an income-related parental benefit up to 70 weeks. Finland and Denmark both have 50 weeks. Iceland has the shortest with less than 40 weeks, and in Norway parents can choose up to 57 weeks. Denmark is the only country with no father's quota, where Iceland has the highest father's quota of 13 weeks.

Iceland and Sweden are in the lead with respectively 28.5 and 25.5 per cent of the number of days taken by the father in 2013. For all the Nordic countries there has been an increase in the father's share of the parental benefits as well as in the number of days taken per new-born in total from 2000 to 2013.

\section{Number of days in which parental benefits where drawn per new-born} 500

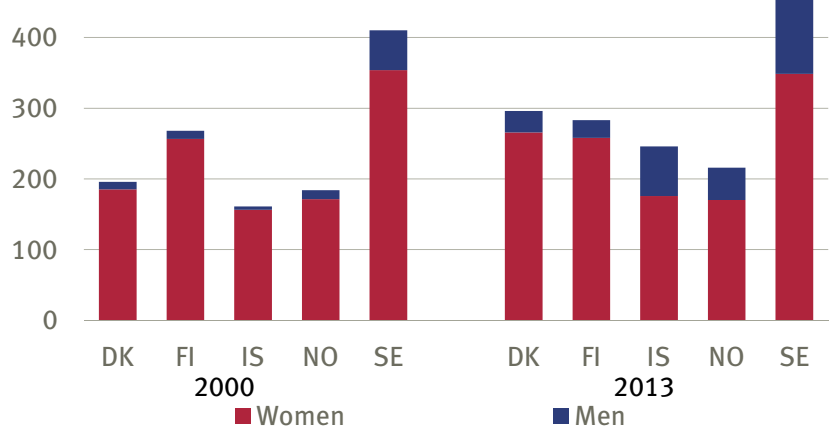

Source: NOSOSCO: "Social protection in the Nordic Countries" 


\subsection{Children in daycare}

A characteristic feature in the Nordic countries is the high rate of both parents participating in the labor force. This increases the need for child care options during working hours.

Most children of the ages 3 to 5 years are in day care institutions. With the exception of Finland, between 92 and 98 per cent of all children age 3-5 are in daycare institutions. This accounts for 74 per cent in Finland. The percentage is generally much lower for children between 0 and 2 years. Due to parental leave very few of the youngest children are in daycare.

\section{Share of children in daycare by age groups}

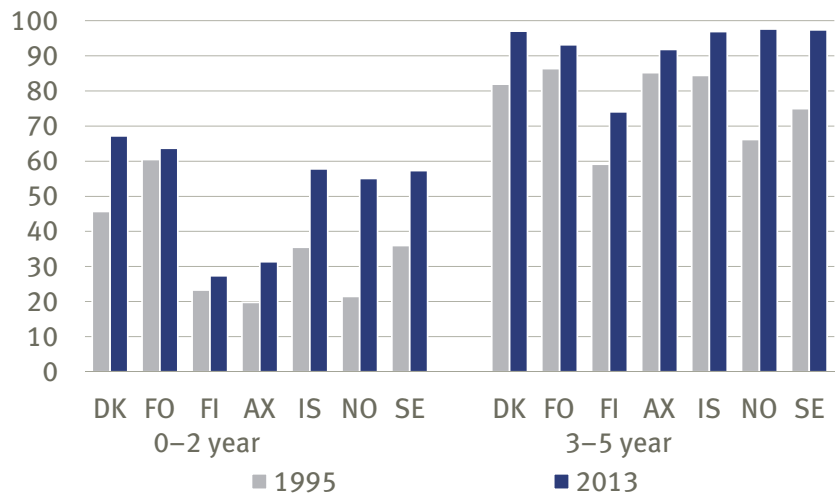

Note: FO: 2004 and 2013. Fl: 1997 and 2013. AX: 2000 and 2013. In 2000 no account for age 0. NO: 1995 and 2012

Source: CHILO3 and POPUO1 in the database Nordic Statistics 


\subsection{Time use on domestic work}

Domestic work includes the work we are doing at home on a day-to-day basis, e.g. cooking and cleaning, repairs and also caring for children. Time is given in hours and minutes, and is shown as the average for all types of domestic work.

Men's time used on household work has increased in all the Nordic countries between 1990 and 2010. Women, on the other hand, are increasingly spending less time on household work. Although the time spent on household work has been more evenly distributed over the last decade, women still contribute significantly more to household work than men.

Time used on domestic work for women and men 20-74 years. Hours 5,0
4,5
4,0
3,5
3,0
2,5
2,0
1,5
1,0

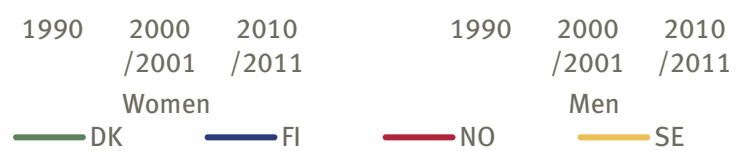

Note: DK domestic work includes the age group 18-74, and it also includes fewer codes for domestic work, than for FI, NO and SE

Source: UNECE, Nordic Statistical Institutes and "Hvad bruger vi tiden til", Rockwool Fonden 2012 


\section{Health}

\subsection{Life expectancy at birth}

The indicator life expectancy at birth indicates how many years a newborn is expected to live, based on the current patterns of mortality. It is frequently used to reflect the health of a population. As the mortality rate differs between women and men (women tend to live longer), life expectancy is calculated separately for women and men.

Even though women still tend to live longer, life expectancy for men is increasing, so the gap is narrowing between the sexes.

Nordic women, except in Denmark and Greenland, have a life expectancy between 83.2 and 84.2 years compared with 83.2 years of the average European woman (EU27). Except for men in Greenland, men in the Nordic countries can expect to live longer than the average European, whose life expectancy is 77.4 years.

\section{Life expectancy at birth. Years. 2013}

\section{0}

85

80

75

70

65

60

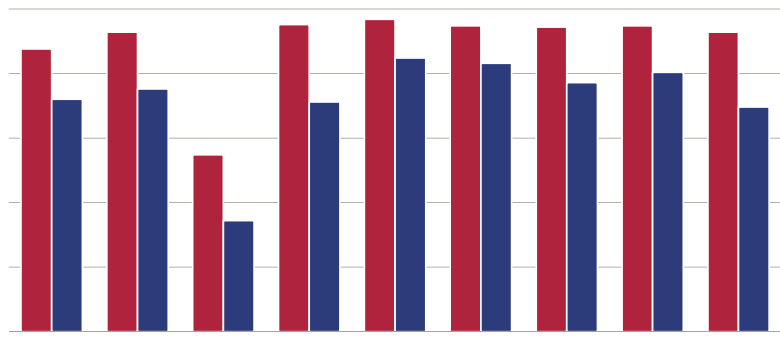
DK
FO
$\mathrm{GL}$
$\mathrm{FI}$
AX
-Women

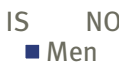
SE EU27

Note: AX 2010 and EU27 2011

Source: INDIC106 in the database Nordic Statistics and NOMESCO: "Helsestatistik for de nordiske lande 2014" 


\subsection{Self perceived limitations due to health problems}

The indicator shows the limitation in activities people usually have due to one or more health problems. The limitation should have lasted for at least the past six months, and is perceived to have either severely limited or limited their activities in daily life (or not limited at all). Health problems may affect people differently by sex and age. Here, the data refers to those with limited or severely limited limitations combined.

Women perceive themselves to have a higher degree of long-standing limitations in their activities than men do. This applies to both age-groups, with the exception of Danish women 65 and over where their share is a little lower than men's. This applies both to the Nordic countries as well as the average for EU28.

There seems to be more differences between countries than between women and men within the countries, reflecting cultural differences in how people perceive their limitations. The proportion of those with perceived limitations is lowest in Norway and highest in Finland.

\section{Self-perceived limitations. Per cent of age group. 2012}

70

60

50

40

30

20

10

0

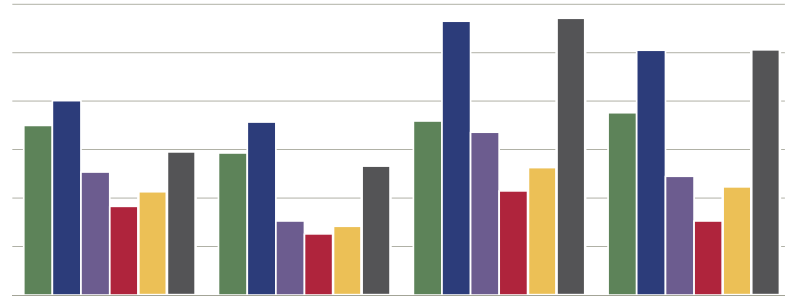

Women

$$
\text { 45-64 Men }
$$

- DK

- $\mathrm{FI} \quad \mathrm{IS}$

- NO

Women

65 and older

Men

Source: Eurostat 


\subsection{Daily smoking}

The indicator refers to the percentage of the population aged 15 years and over who report smoking every day - with slight deviations in age groups for the different countries. Smoking is one of the life style factors that has an impact on the status of health. Smoking habits of women and men can be reflected in different patterns of illnesses and mortality.

The proportion of daily smokers has decreased for both women and men in all the Nordic countries and in some of them by half since 1995. Men used to smoke more than women and this is still the case in Denmark, Norway and Finland, but in Iceland and Sweden a higher percentage of women than men are daily smokers, although the difference is small. The highest percentage for female smokers is in Denmark with 15.5 per cent and for male smokers it is in Finland with 20.9 per cent.

\section{Daily smokers. Per cent of ages 15 and over}

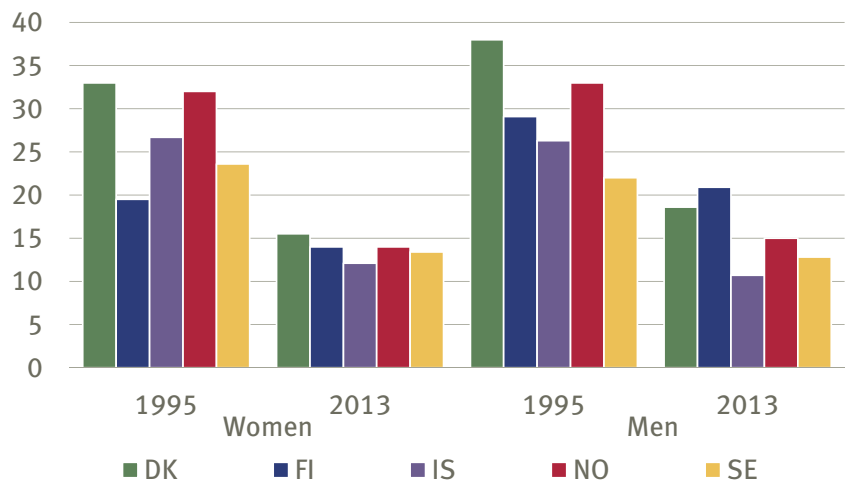

Note: Fl and SE 2012

Source: OECD 


\subsection{Mortality rates from cancer}

The indicator refers to the mortality rate from cancer (malignant neoplasms) which is one of the main groups of causes of death covering many different types of cancer. It accounts for one-fourth of all deaths in the Nordic countries. Mortality rate is the number of deaths per 100000 of the average population. Mortality rates differ by gender and are generally shown separately for women and men.

In all the Nordic countries the mortality rates for cancer are higher for men than women. Greenland accounts for the lowest gender difference where the rates for women and men are almost the same, whereas the Faroe Islands, Finland and Iceland have the highest gender difference. The highest cancer mortality rates for both women and men are in Denmark, where 262 women and 289 men per 100000 died from cancer (2012). The lowest rates are in Iceland, where 160 women and 192 men per 100000 died from different types of cancer (2009).

Mortality rates from cancer. Per 100 000. 2012

350

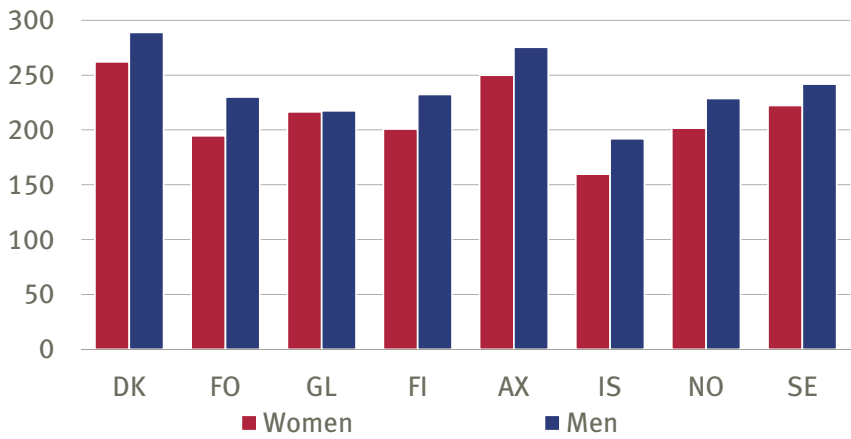

Note: FO, GL and AX average 2008-2012. IS 2009

Source: HEALO3 in the database Nordic Statistics and NOMESCO 


\subsection{Mortality rates from diseases of the circulatory system}

The indicator refers to the mortality rate from the diseases of the circulatory system which is one of the main groups of causes of death. It accounts for one-third of all deaths in the Nordic countries. Mortality rate is the number of deaths per 100000 of the average population.

Different from cancer mortality women have higher mortality rates than men from the diseases of the circulatory system in all the Nordic countries, except the Faroe Islands, Iceland and Greenland. The gender gap for these causes of death is the narrowest in Denmark but the widest in Åland. The mortality rate for women is the highest in Åland 410 deaths per 100000 people, followed closely by Finland and Sweden and the similar accounts for the mortality rates of men. The rates are at a lower level in the other countries with the lowest being in Greenland, both for women and men with 158 and 199 deaths per 100 000, respectively.

Mortality rates from diseases of the circulatory system. Per 100000. 2012 500

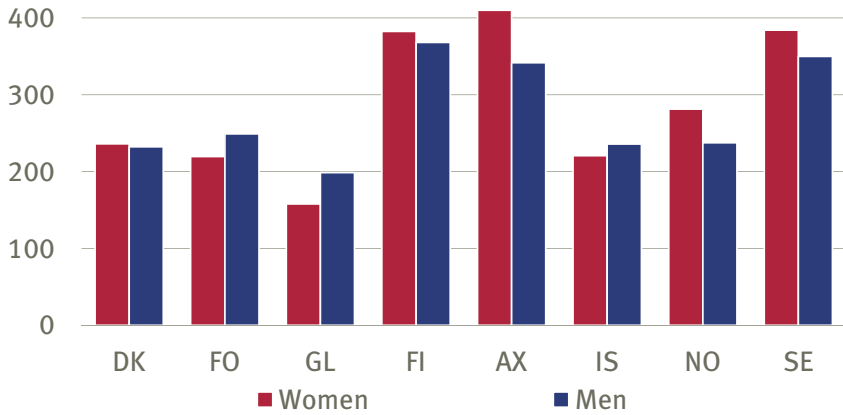

Note: FO, GL and AX average 2008-2012. IS 2009

Source: HEALO4 in the database Nordic Statistics and NOMESCO 


\subsection{Suicides}

The indicator refers to the mortality rate from suicides. The mortality rate is the number of deaths per 100000 of the average population. Mortality rates differ by gender and are generally shown separately for women and men. Practices for coding suicides differ from one country to another and, thus, comparisons of mortality rates from suicides should be made with caution.

Suicides are more common among men than women. The rate of suicides has generally declined in the Nordic countries, both for men and women. It is by far the highest in Greenland and that accounts for both men and women. Finland has the second highest rate of suicide for men or 25 per 100000 , followed by Iceland and Sweden. The lowest rate for both women and men is in the Faroe Islands, one for women and eight for men. The rate of suicide for women, is between one and ten per 100000 in the Nordic countries apart from in Greenland.

\section{Number of suicides per 100000}

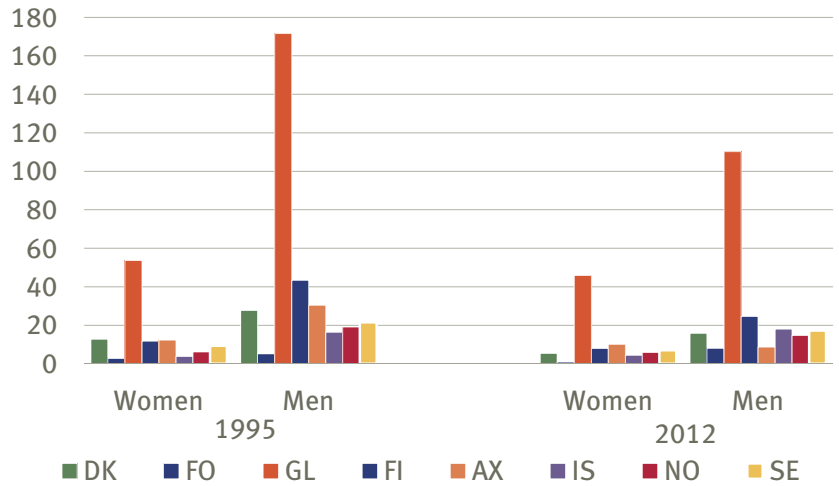

Note: FO, GL and AX 1996 and 2011. Average 2007-2011. IS 1995 and 2009

Source: HEALO5 in the database Nordic Statistics 


\subsection{Abortion}

Total abortion rate refers to the number of legal abortions performed on 1000 women during their fertile period (from 15-49 years).

Since the mid-1970s induced abortions have been available in most Nordic countries. In Denmark, Greenland, Norway and Sweden, it is entirely up to the pregnant woman in the early stages of pregnancy to determine whether to have an abortion. In the Faroe Islands, Finland, Åland and Iceland, a leave based on social and/or medical criteria is required.

The total abortion rate has decreased in all the Nordic countries between 2000 and 2012, except for Sweden, Åland and Denmark. Greenland has the highest total abortion rate with 2014 abortions per 1000 women during their reproductive period (from 15-49 years). Sweden has the second highest rate at 621. The Faroe Islands has the lowest rate at 133.

\section{Total abortion rate}

2500

2000

1500

1000

500

0
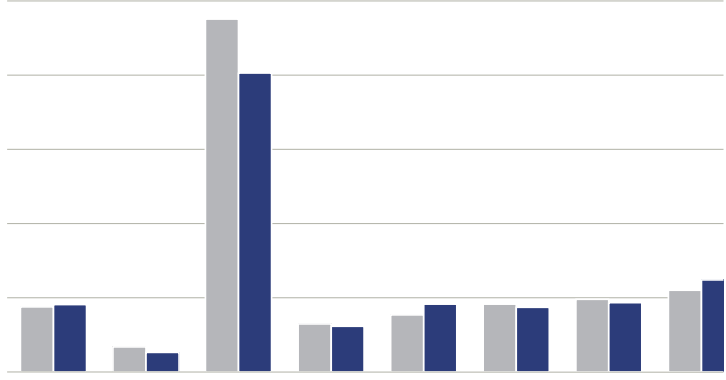

DK FO GL

$\mathrm{FI}$

AX

IS NO

SE

2000

2012

Note: FO 2000 and 2008. GL and AX 2000 and 2009. IS 1999 and 2012

Source: HEAL15 in the database Nordic Statistics 


\subsection{Absence from work for at least a week due to illness}

The indicator shows absence from work for at least a week because of illness calculated as per cent of all employed. The figures have been calculated on the basis of labor force surveys as an average of the censuses. In principle, everyone with gainful employment is entitled to daily cash benefits in the event of illness. The structure varies considerably by country. Benefits paid in connection with illness are taxable in all countries.

The percentage of absence from the workplace due to illness for more than one week is generally higher for women than men with the widest gap in Norway and the narrowest in Denmark. Absence is markedly the highest in Norway for both women and men in 2013 , or 4.3 per cent and 2.7 per cent, respectively, and has increased compared with 1995 . The per cent of absence has decreased for both sexes in Sweden and increased in Finland. Iceland and Denmark account for the lowest absence.

\section{Absence from work for at least a week due to illness. Per cent of all employed}

5

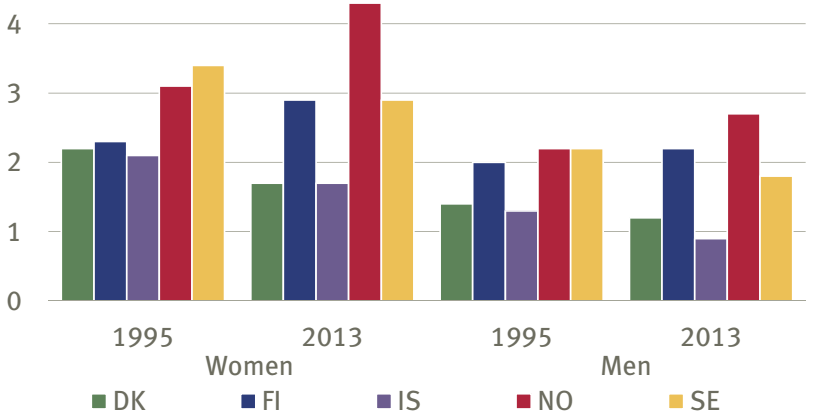

Note: DK aged 15-66 years

Source: SOCIO2 in the database Nordic Statistics 


\section{Education}

\subsection{Educational attainment}

The indicator defines the per cent of the population aged $15-74$ years who have reached ISCED (International Standard Classification of Education) levels 1-6. Not specified education is categorised together with Primary education.

In 2012 almost 57 per cent of the people who attained a higher education at tertiary level were women. Comparisons between sexes in educational attainment show a lower educational level for men than for women. This is partly due to male-dominated vocational training and education not being counted in tertiary level. Finland and Norway have the highest proportion in tertiary education for both women and men. Sweden has the highest share of women and men in upper and post-secondary education. The proportion of people having a tertiary education has increased in all the Nordic countries as well as in the EU since the late 1990s.

Educational attainment/Level of education attained, people aged 15-74 years. Per cent

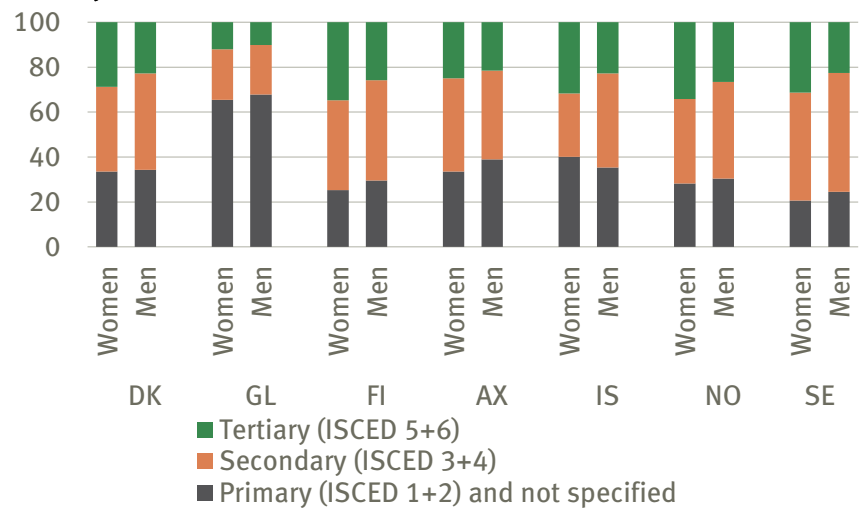

Source: EDUCO1 in the database Nordic Statistics 


\subsection{Early leavers from education and training}

Early leavers from education and training are defined as the proportion of the population aged 18 to 24 with a lower secondary level of education as the highest attained and who are no longer in further education or training.

EU has adopted a benchmark share of less than ten per cent early leavers from education and training to be achieved by 2020. In Sweden, Finland and Denmark the proportion of early leavers is lower than the EU28 average at 12.7 per cent, but in Norway (only boys) and in Iceland the shares are higher. The higher drop-out rate for young boys has in particular been debated in many European countries during the last decade. In all the Nordic countries boys have a higher share of early leavers than girls, when the gender differences are compared in each country. However, there is a higher share of early leavers among Norwegian and Icelandic girls, than of Swedish, Finish and Danish boys.

\section{Early leavers from education and training by sex. Per cent}

25

20

15

10
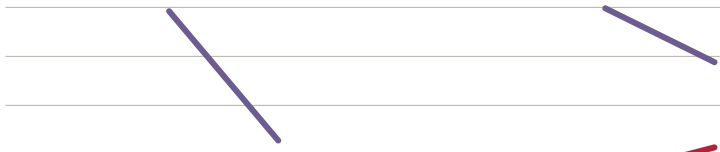

5

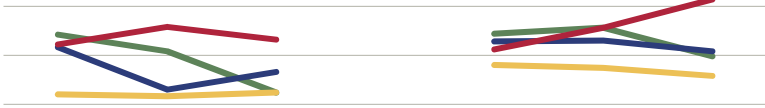

0

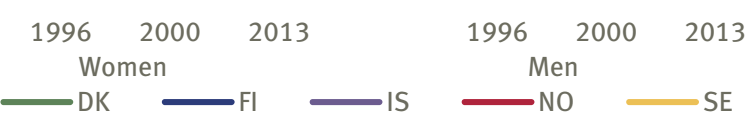

Source: Eurostat 


\subsection{Graduated students at tertiary level}

The indicator shows the share of graduated students with tertiary level for women and men in 2012.

In the Nordic countries the majority of graduates at tertiary level (ISCED 5 \&

6) are women. Men account for less than 40 per cent of those graduating. In Sweden 45 per cent of the female graduates from 2012, graduated at the tertiary level, which is the highest share in the Nordic countries. For men the proportion is the highest in Sweden as well, 34 per cent. Åland has the lowest share of graduated students at this level, for both men and women.

Graduated students. Per cent with tertiary level. 2012

50

40

30

20

10

0

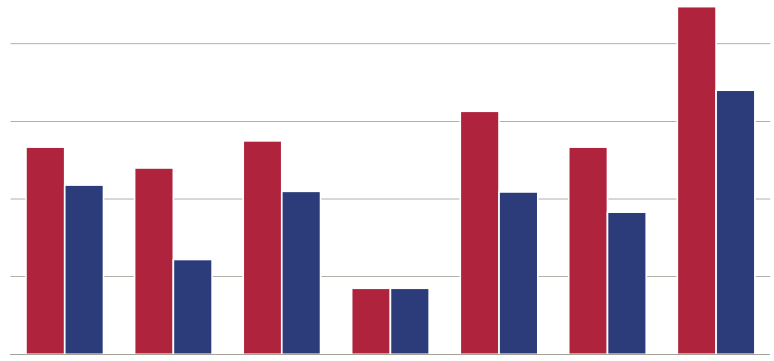

DK

$\mathrm{GL}$

$\mathrm{FI}$

- Women

AX

IS

- Men

Note: SE 2011

Source: EDUCO3 in the database Nordic Statistics 


\subsection{Attained tertiary education by field of education}

The indicator shows the gender distribution in the six largest fields of education in 2012.

Female graduates dominate within fields such as health and social services, whereas males dominate in fields such as engineering, manufacturing and construction. The share of men in health, education and social services is still very low in all the Nordic countries. The share of women in engineering, manufacturing and construction is also still low, but increasing. Teacher training and education science are common fields for women in Iceland and Norway, but it is also more common for men in these two countries than in the other Nordic countries.

Tertiary education attained by field of education. Per cent. 2012

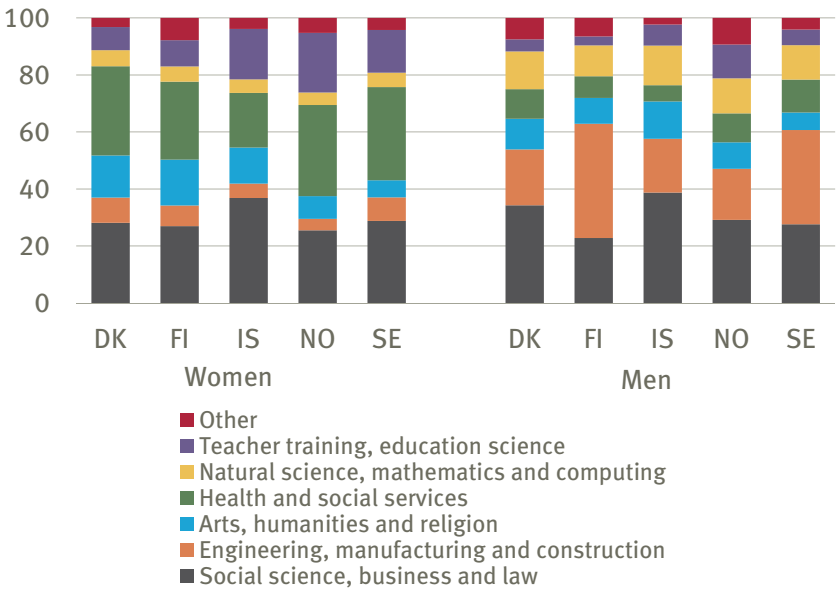

Source: EDUCO3 in the database Nordic Statistics 


\section{Labour market}

\subsection{Labour market status}

The employment rate is the percentage of employed persons of the population. The EU 2020 goal for the employment rate, for both women and men aged $20-64$, is 75 per cent. Among the Nordic countries, Iceland, Norway and Sweden have already reached the target in that age group.

For age group 15-64 it looks slightly different. Men in the Faroe Islands, Iceland, Sweden, Norway and Denmark have achieved the goal, but the other countries have a long way to go. Among women, only women in the Faroe Islands, Iceland and Åland have an employment rate of 75 per cent or more.

Åland and Norway has the lowest unemployment rate, 2 and 3 per cent respectively for both women and men. Other Nordic countries have an unemployment rate between 6 and 7 per cent. Finland has the highest proportion of both women and men, who are outside the labour force. They are neither employed nor unemployed.

\section{Labour market status, aged 15-64 years. 2013}

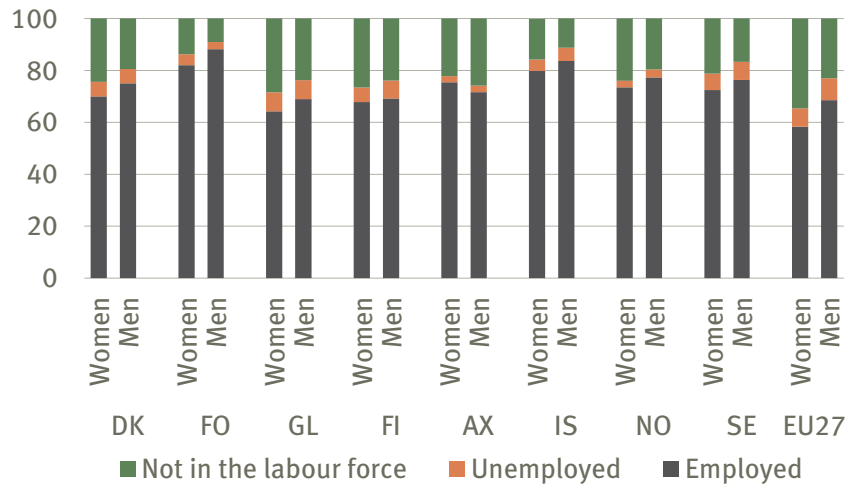

Note: GL 2012 and AX 2011

Source: WORKO2 in the database Nordic Statistics 


\subsection{Segregation}

The labour market in the Nordic countries is highly segregated by sex. The indicator shows the share of all employed women and men in, respectively, the largest female-dominated industries "Education" and "Human Health and Social activities," and the largest male-dominated industries , "Manufacturing”, “Construction" and "Transportation and Storage”.

The two female-dominated industries employ in total just above one quarter of all employed in the Nordic countries. 43 per cent of all employed women work in these two industries, but just 11 per cent of all employed men.

The opposite prevails in the three male-dominated industries, which in total employ almost one quarter of all employees. These three industries employ 37 per cent of all employed men, and 10 per cent of all employed women.

\section{Per cent of employed aged 15-64 years in the largest female- dominated and male-dominated industries. 2013}

50

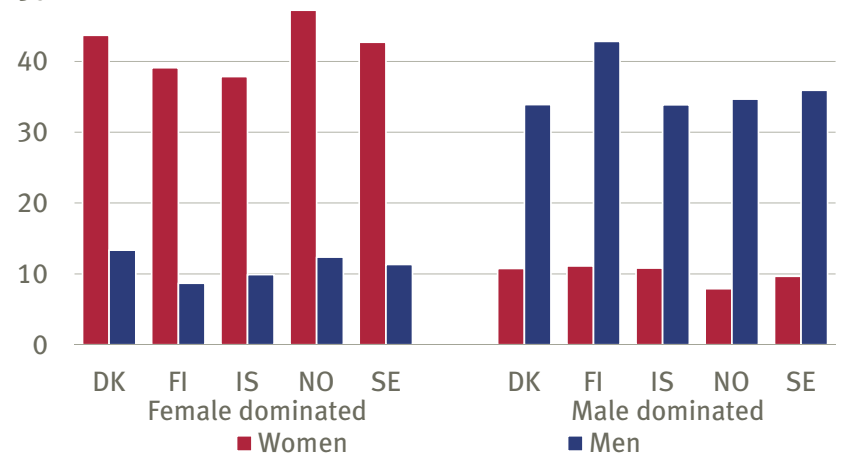

Source: Eurostat 


\subsection{Part-time work}

Working part-time facilitates the possibility to combine gainful employment with parenthood or studies. In some industries, it is more common with part-time employment than in others, for example health-related work.

The proportion of women working part-time has decreased in Norway, Sweden and Iceland since 1995, but increased in Finland. In Finland, the proportion of part-time working women is significantly lower than in the other Nordic countries.

Among men, the proportion of part-time workers increased in all the Nordic countries, except for Iceland where it has fallen.

The highest proportion of part-time working men can be found in Denmark and the lowest proportion in Finland.

\section{Per cent of employed aged 15-64 in part-time employment}

60

50

40

30

20

10

0

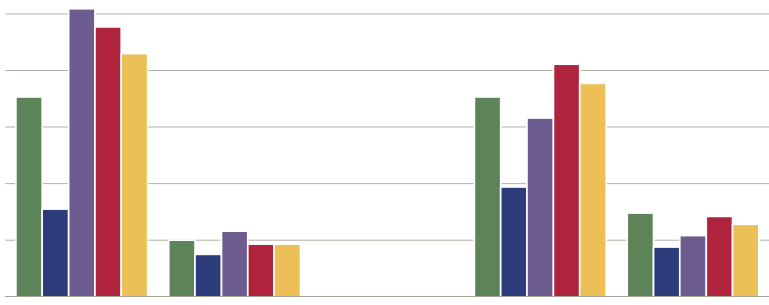

Women

Men

Women

Men

1995

- DK

- $\mathrm{Fl}$

- IS

- NO

2013

Source: $\angle A B O O 3$ in the database Nordic Statistics 


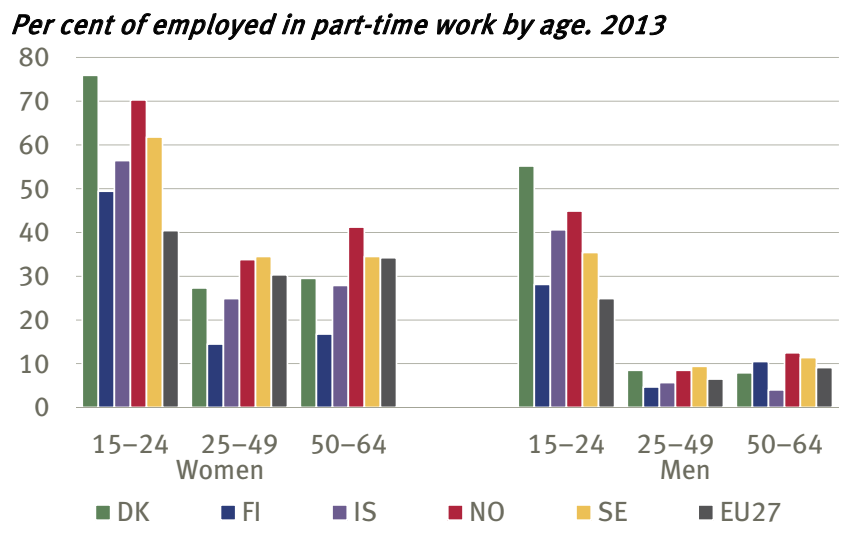

Source: Eurostat

Regardless of age, women work part-time to a higher degree than men, and this has been the case for many decades.

In all countries but Finland, both women and men in the younger ages have increased their part-time work since 1995 . Women have reduced their proportion of part-time work in the other age groups in all countries but Finland.

Men aged 25-49 work part-time to a higher degree in all countries since 1995, except for Iceland. At the older ages 50-64, men work part-time to a higher degree in Denmark, Finland and Norway, while men in Sweden and Iceland have reduced their part-time work since 1995. 


\section{Income}

\subsection{Gender pay gap}

The unadjusted Gender Pay Gap represents the difference between average gross hourly earnings of male paid employees and of female paid employees as a percentage of average gross hourly earnings of male paid employees.

The gender pay gap in Denmark, Norway and Sweden is around 15 to 16 per cent, a little narrower than the average for the EU, at 16 per cent. The gap is slightly wider in Finland and Iceland. The gap has been stable or reduced in all the Nordic countries from 2011 to 2012. From 2010 to 2011, the gap widened in Denmark, but has decreased again in 2012, and Denmark has now the narrowest gap in the Nordic countries.

\section{Gender pay gap}

25

20

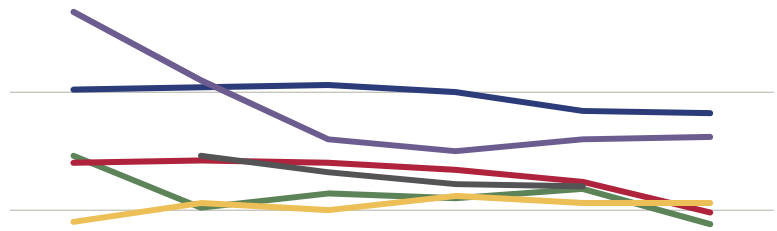

10

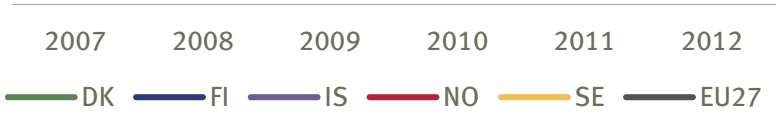

Source: INDIC109 in the database Nordic Statistics 


\subsection{Mean annual earnings}

Mean annual earnings are the gross annual earnings of employees, calculated for both full-time and part-time employees, as full-time equivalents.

In 2010 Iceland had the largest gender wage gap (in purchasing power) among the Nordic countries, in terms of women's share of men's earnings. Iceland was at the same time the country with the lowest wage level for both sexes, lower than the level of the EU27. Also Finland had a relatively large wage gap between men and women, while in Sweden the gap was the smallest. This is due to a generally lower wage level among Swedish men in 2010, compared to the wage level of men in Denmark, Norway and Finland. Denmark was the country with the highest wage level, for both men and women, but the gender gap was still relatively large compared to that of Norway and Sweden.

Mean annual earnings. PPS in Euro. 2010

50000

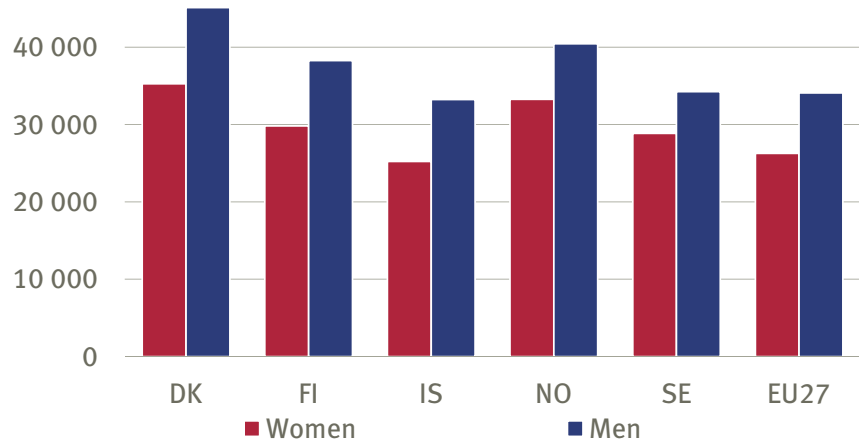

Note: PPS: Purchasing Power Standards eliminates the differences in price levels between the countries.

Source: Eurostat 


\subsection{People at risk of poverty}

The indicator measures the proportion of men and women at risk of monetary poverty. Monetary poverty is a key dimension of social inclusion. Persons are at risk of poverty if their equivalised disposable income is below the risk-of-poverty threshold, which in the EU is set at 60 per cent of the national median income after social transfers.

The number of people at risk of poverty or social exclusion has increased in all Nordic countries in recent years, with the exception of Iceland. The most dramatic increase in the five-year period from 2008-2013 has been for Swedish women. One in six Swedish women was at risk of poverty in 2013, compared to less than one in ten Icelandic women. In Denmark and Iceland more men than women were at risk of poverty in 2013.

People at risk of poverty or social exclusion. Percentage of total population

20

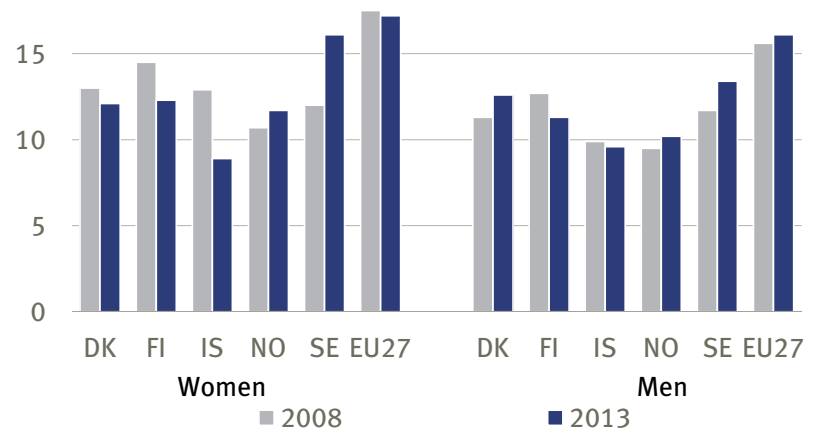

Source: Eurostat 


\subsection{Relative median income ratio}

The relative median income ratio is defined as the ratio of the median equivalised disposable income of people aged above 65 to the median equivalised disposable income of those aged 65 years or below.

In all the Nordic countries the average income of women and men above 65 years, was less than the average for those under 65 . The gap was the greatest for Denmark and Finland. Also, in all the Nordic countries the average income of women under 65 was below that of men in the same age group. The gender gap is on average about ten percentage points in men's favour. The gender gap in income for this age group is often more pronounced in countries where a relatively large proportion of women live alone, which is more common in the Nordic countries than in many other European countries.

\section{Relative median income ratio for people aged above 65. 2013}

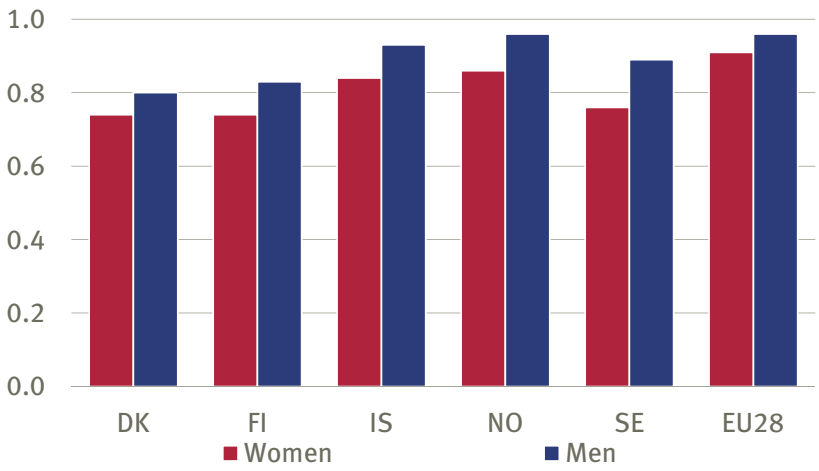

Source: Eurostat 


\section{Influence and power}

\subsection{Candidates elected to the national parliaments}

The indicator shows the gender distribution of seats in the national parliaments in the Nordic countries after the latest election in each country.

Most of the Nordic countries have a relatively balanced gender representation in their parliaments, with an average female representation of 40 per cent. The average in the EU was 23 per cent in 2013. Sweden has the highest female representation, with 45 per cent. Åland and the Faroe Islands have a considerably lower female representation than the other Nordic countries. Åland is slightly below the EU average. All Nordic countries have a proportional representation system.

\section{Candidates elected to the national parliaments, latest election}

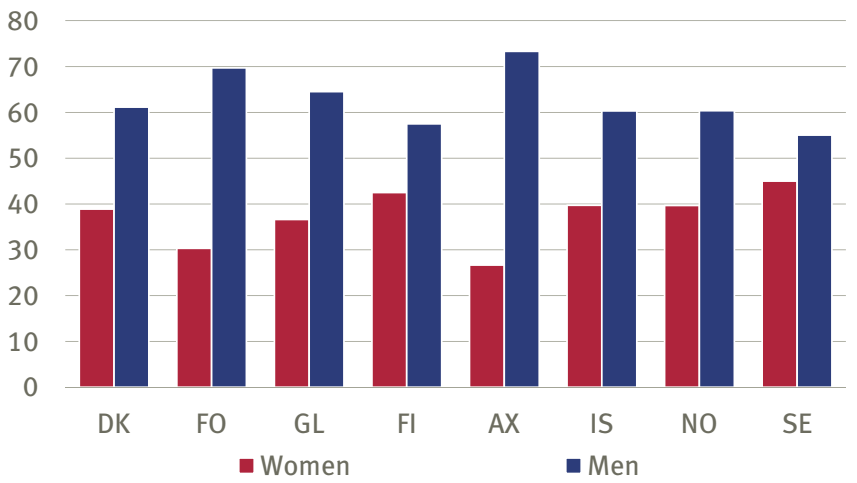

Source: ELEO3 in the database Nordic Statistics 


\subsection{Gender balance on boards}

The indicator shows the gender balance on boards of the largest publicly listed companies in the Nordic countries. Publicly listed means that the shares of the company are traded on the stock exchange. Norway and Iceland have passed legislation to secure gender balance on such boards.

On average, about three of ten board members of the largest publicly listed companies in the Nordic countries are women. In 2014 Iceland and Norway had the highest female share among the Nordic countries, at 46 and 40 per cent. Denmark had the lowest share at 23 per cent.

\section{Women and men on boards of listed companies. Per cent. 2014} 100

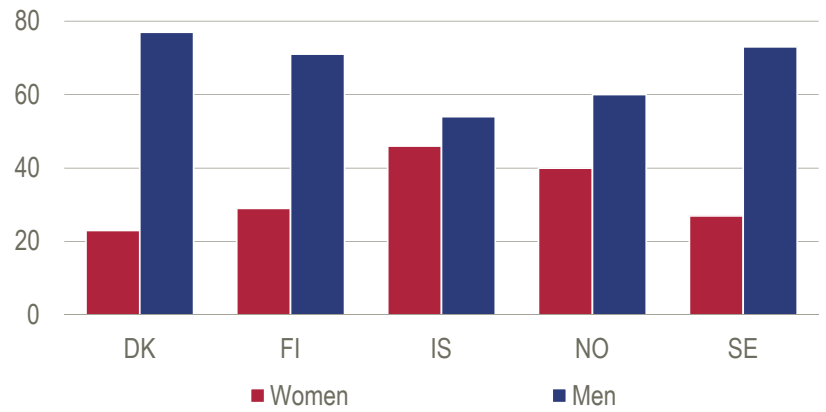

Source: European Commission, database on men and women in decision making 


\subsection{Gender differences among employers}

The indicator shows the percentage of employers among all employed women and men.

In the Nordic countries the share of employers is significantly higher among men compared to women. The highest share of female employers was found in Iceland where just over two per cent of the employed women are employers. Norway had the lowest share, one per cent. This could however, also be a reflection of the general low share of employers among Norwegian employees. Two per cent of Norwegian employed men are employers compared with six per cent of Finnish men. The share of female employers has grown in Norway and Sweden over the last decade, while in Denmark, Finland and Iceland it has decreased. In this period the share of male employers with employees has increased in Norway and Finland but decreased in the other Nordic countries.

\section{Employers. Per cent of all employed}

10

8

6

4

2

0

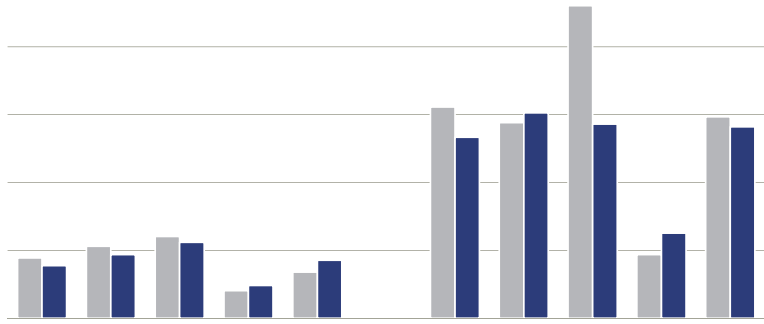

DK FI $\begin{gathered}\text { IS NO SE } \\ \text { Women }\end{gathered}$ DK FI $\begin{aligned} & \text { IS NOn } \\ & \text { Men }\end{aligned}$

$\square 2002$

- 2012

Source: $O E C D$ 


\subsection{Leaders and managers}

Managers include all employees with managerial responsibilities (ISCO 08, occupation code 1).

The proportion of women managers is still below 40 per cent for all the Nordic countries in 2013. Iceland has the highest proportion of female managers, 37 per cent. Denmark has the lowest share, 29 per cent. In the EU the share of female managers is on average 33. However, there has not been any major change in increasing the share of female managers during the last decade. This chart shows the sex distribution among managers at all levels. The proportion of women in top management is known to be considerably lower.

Share of women among employed persons with managerial responsibilities

50

40

30

20

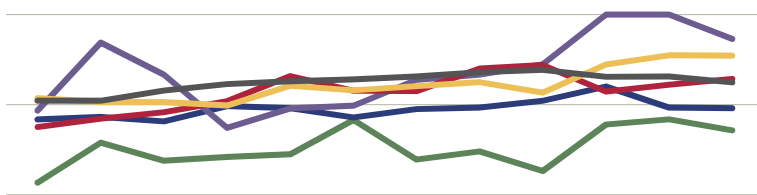

10

$2002 \quad 2004 \quad 2006 \quad 2008 \quad 2010 \quad 2012$

$\longrightarrow \mathrm{DK} \longrightarrow \mathrm{FI} \longrightarrow \mathrm{IS} \longrightarrow \mathrm{NO} \longrightarrow \mathrm{SE} 28$

Source: $O E C D$ 


\section{norden}

\section{Nordic Council of Ministers}

Ved Stranden 18

DK-1061 Copenhagen K

www.norden.org

This brochure gathers information on gender equality in the Nordic region. It briefly describes some important areas of life and society, such as family, work, education, health, power, income and influence. This data will hopefully be useful for everyone who seeks reliable and comparable data on gender equality in the Nordic countries. Please visit www.norden.org for more information.

ISBN 978-92-893-4039-7 (PRINT)

ISBN 978-92-893-4040-3 (PDF)

ISSN 0908-4339

http://dx.doi.org/10.6027/ANP2015-733 ANP 2015:733 